\title{
Computer Control Algorithms for a Tubular Ammonia Reactor
}

\author{
L. M. PATNAIK, MEMBER, IEEE, N. VISWANADHAM, AND ISUKAPALLI G. SARMA, SENIOR MEMBER, IEEE
}

\begin{abstract}
The specific objective of this paper is to develop direct digital control strategies for an ammonia reactor using the quadratic regulator theory and compare the performance of the resultant control system with that under conventional PID regulators. The controller design studies are based on a ninth-order state-space model obtained from the exact nonlinear distributed model using linearization and lumping approximations. The evaluation of these controllers, with reference to their disturbance rejection capabilities and transient response characteristics, is carried out using hybrid computer simulation. The linear state-space model is simulated on the analog processor of the AD511 hybrid computer and the control algorithms are implemented on the digital computer.
\end{abstract}

\section{INTRODUCTION}

HE specific objective of this paper is to present several single variable and multivariable discrete control algorithms for a tubular reactor used in ammonia synthesis and evaluate their performance characteristics. The tubular reactor where the main reaction takes place is the heart of the ammonia plant and thus critically affects the economic and safe operation of the process. Studies relating to its optimization and control therefore acquire utmost practical interest. In an earlier paper [1], the authors have developed an optimization program to determine the optimum temperature profile that maximizes the ammonia yield. The reactor is to be operated at the "blow-out" point (highest temperature stable operating point) to achieve higher throughput. However, the feed concentration and temperature disturbances tend to change the temperature profile inside the reactor and thus drive the reactor away from this maximal yield operating point. Hence, regulation of the temperature along the length of the reactor around the optimal profile in the presence of disturbance inputs is important and forms a dominant design objective for control system design.

Earlier control system design studies [2], [3] concerning the ammonia reactor concentrate on tuning of PID controllers using simplified models. We demonstrate in this paper that use of this type of conventional controllers regulate the temperatures only at the points where the controllers are implemented. Here, we follow a more rigorous approach to obtain linear continuous state-space

Manuscript received March 14, 1979; revised May 15, 1979 and March 3, 1980. Paper recommended by H. A. Spang, III, Past Chairman of the Applications, System Evaluation, and Components Committee.

The authors are with the School of Automation, Indian Institute of Science, Bangalore, 560012 India. models from the exact distributed model invoking linearization and lumping approximations. The model has three control inputs (flow rates), two disturbance inputs (concentration and temperature variables), and nine state variables (temperatures). The model development is briefly discussed in Section II. Also in this section a discrete state-space model is obtained for subsequent use. The selection of the controller parameters when the PI controllers are located at the top end, bottom end, and at both ends of the reactor is considered in Section III. In Section IV we consider the feedforward and integral controller designs using the discrete quadratic regulator theory.

The evaluation of the control system structures considered in earlier sections is done via hybrid simulation. The linear model is simulated on the analog computer and the control law calculations and execution is done by the digital section. A comparative study of the simulation results is presented in Section $V$.

\section{Reactor Description and Model Equations}

Fig. 1 shows the schematic of the ammonia synthesis reactor under consideration which is currently under continuous PID control in an operating plant. The data for this reactor is given in [1]. The converter consists of two parts: 1) the catalyst bed section shown in the upper part of the diagram, and 2) the heat-exchanger section shown in the lower part of the diagram. To ensure stable conditions with maximum yield, it is necessary to heat the feed gases to a temperature of about $420^{\circ} \mathrm{C}$ before they enter the catalyst bed. This is economically achieved by preheating the feed gas first in the bottom heat exchanger and subsequently in the tubes of the reacting section. The inlet gaseous mixture is split into three separate streams: 1) the heat exchanger flow, 2) the second stream called the heat exchanger bypass flow, and 3) the third stream known as the direct bypass flow. The feed gases flowing down the catalyst bed react to produce ammonia. The outlet gases from the reacting portion enter the tubes of the heat exchanger and finally exit through the converter. Adequate instrumentation exists to measure the process variables of interest. The temperature at five points along the length of the reactor bed are measured using thermocouples. Also the inlet flows are measured using differential pressure type flow meters. The concentration variables 


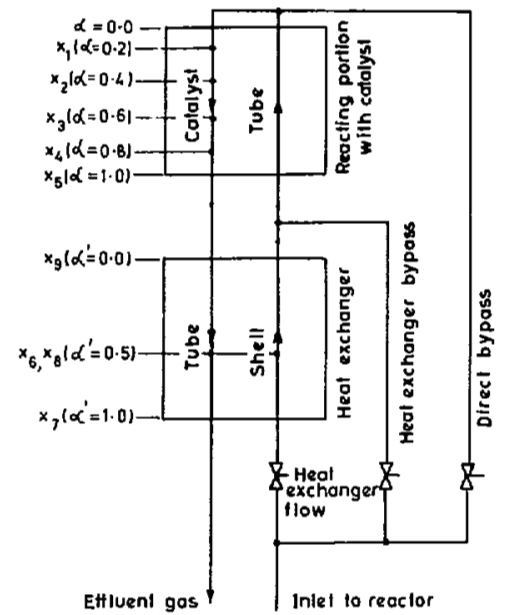

Fig. 1. Schematic of the synthesis converter.

are obtained, however, off-line from periodically collected samples.

A nonlinear distributed model of the reactor described above is developed using mass and energy balance principles and consists of five partial differential equations and two algebraic mixing equations (see Appendix I). The boundary conditions associated with these differential equations are time varying and some are specified at $\alpha=0$ and some at $\alpha=1$, where $\alpha$ is the normalized distance variable. The method followed to derive the model equations is the same as in [5]. Because of the time varying split boundary conditions, development of converging iterative solutions to the model equation is a formidable task even when using hybrid computers which are best suited for this purpose. Furthermore, control system design using this model is mathematically intractable. Thus, we resort to model simplification via linearization and lumping. The model equations are linearized around the steady-state operating point corresponding to maximum yield. The steady-state flow rates and the optimum temperature profile that maximizes the yield of the reactor are given in [1]. We further simplify this linearized distributed model of the reactor and heat exchanger combination by discretizing the length of the reactor into five equal segments and the heat exchanger into two equal segments. The steady-state temperature profile of this lumped model is obtained and compared with that obtained from the nonlinear steady-state model [1]. Based on the error in the temperature profile, it is observed that no significant improvement in model accuracy can be obtained by increasing the number of segments beyond seven, and the lumped model is unstable when the number of segments is reduced to three. Thus, the number of segments is fixed to be seven. The details of these aspects may be found in [4]. This linear model is simulated on the analog processor to represent the process dynamics. Gould et al. [11] consider the linearized form of system equations to derive a "Taylor diffusion model" which approximates the system by a single constant-coefficient diffusion equation. The eigenfunctions of the Taylor diffusion model are used to approximate those of the original system. By neglecting the high-order mode content, the dynamic system is approximated by a finite dimensional state model. Even though they consider two modes and one manipulated variable, there is no demonstration of a test to check the accuracy of the linear model. It is somewhat difficult to use this technique to diffusionless processes and systems with appreciable time delay. The choice of the optimum number of modes is not easy. Moreover, their study deals with continuous proportional control of the reacting portion only.

The discretized ordinary differential equations obtained above can be rearranged in the state-space form

$$
\dot{x}(t)=A x(t)+B u(t)+D d(t)
$$

where $x(t)$ is a $9 \times 1$ state vector representing the incremental temperature along the reactor-heat exchanger, $u(t)$ is a $3 \times 1$ manipulated variable representing the three flow rates, and $d(t)$ is a $2 \times 1$ disturbance vector of inlet temperature and ammonia composition.

In other words

$$
\begin{aligned}
& x^{T}=\left[t_{c}(1), t_{c}(2), t_{c}(3), t_{c}(4), t_{c}(5), t_{t}^{\prime}(1), t_{t}^{\prime}(2), t_{s}^{\prime}(0), t_{s}^{\prime}(1)\right] \\
& u^{T}=\left[u_{1}, u_{2}, u_{3}\right] ; \quad d^{T}=\left[t_{f}, y_{0}\right] .
\end{aligned}
$$

The matrices $A, B$, and $D$ are given in Appendix II.

In computer control systems, the control input generated by the computer remains constant between the sampling instants. Using this fact, the discrete model is derived from its continuous counterpart for the chosen sampling time of $30 \mathrm{~s}$. The discrete model is governed by

$$
\begin{aligned}
x(k+1) & =\Phi x(k)+\Delta u(k)+\Theta d(k) \\
y(k) & =C x(k)
\end{aligned}
$$

where

$$
e^{A T} \triangleq \Phi, \quad \int_{0}^{T} e^{A \tau} B d \tau \triangleq \Delta \text { and } \int_{0}^{T} e^{A \tau} D d \tau \triangleq \Theta .
$$

In (3), $k T$ is the sampling instant and $T$ is the sampling period. The matrices $\Phi, \Delta$, and $\Theta$ are as given in Appendix II.

\section{Design Objectives and Controller Design}

As mentioned in the introduction, the control system should be capable of maintaining the temperature profile of the reactor close to the steady-state optimal case in the face of disturbance. In terms of the incremental model [see (3)], this would imply that the states $x_{1}$ to $x_{5}$ should be regulated around the origin. Thus, the specific design problem is one of choosing either feedforward or integral control laws that achieve asymptotic disturbance rejection and good transient behavior. However, for the existence of such controllers the linear model (3) has to satisfy the conditions [6] of 1) stabilizability, 2) the number of outputs to be regulated being equal to or less than the number of control inputs, and 3) no transmission zeros lying on the unit circle. Since the control input vector is of 
dimension three, we can choose only three of the five states representing the reactor temperatures as the controlled variables. However, for every choice of three out of five of these states as outputs, the plant model has zeros on the unit circle. Using the design approach suggested in [6], it is not possible to force the steady-state offsets at three points along the reactor length to be zero. Staats $e t$ al. [9] have proposed a technique to design continuous regulators using the transmission zeros at the origin. It is observed that [10] for the continuous system the above design yields a regulator which can maintain the temperatures at zero at three points, whereas the continuous counterpart of the approach followed in this paper can maintain temperatures at zero at two points, and at the third point the deviation is within specified limits. The alternate approach adopted in this paper is computationally simpler.

The only alternative then is to consider a model with only two outputs. We choose the states $x_{1}$ and $x_{5}$ representing the incremental temperatures at the top and bottom ends of the reactor as the controlled variables, with the hope that if the offsets at these points are maintained at zero, then the offsets at intermediate points would lie within tolerable bounds. This is indeed confirmed by the simulation studies. We carry out the multiloop PI controller, multivariable feedforward, and integral controller designs for the model with $x_{1}$ and $x_{5}$ as outputs and $u_{2}$ and $u_{3}$ as control inputs while keeping $u_{1}$ at the steady-state optimal value.

Specifically, we consider the design and performance comparison for the following cases:

1) PI and PID controller to control temperatures at 1) $\alpha=0.2$ and 2) $\alpha=1$

2) multiloop PI controller to control temperatures at $\alpha=0.2$ and $\alpha=1$

3) multivariable state feedback controller based on quadratic regulator theory

4) multivariable feedback-feedforward controller

5) multivariable proportional-integral controller.

In case 1), following the practice at the plant from where the data is taken, the design is carried out using the ninth-order state-space model with direct bypass flow rate $\left(u_{3}\right)$ as the control input while the other two control inputs are held constant at their optimal steady-state values.

\section{A. Discrete PI Controller}

Since the practice in most of the ammonia plants is to use single variable continuous or discrete controllers, we consider the tuning of discrete controllers located at the top and bottom ends of the reactor using the direct bypass rate as the control input. It is observed that this flow rate has the maximum influence on the temperature profile of the reactor. The other two flow rates remain at their steady-state optimal values. In designing these control laws, we consider the following discrete equivalent of the continuous PID controller employing a rectangular integration scheme:

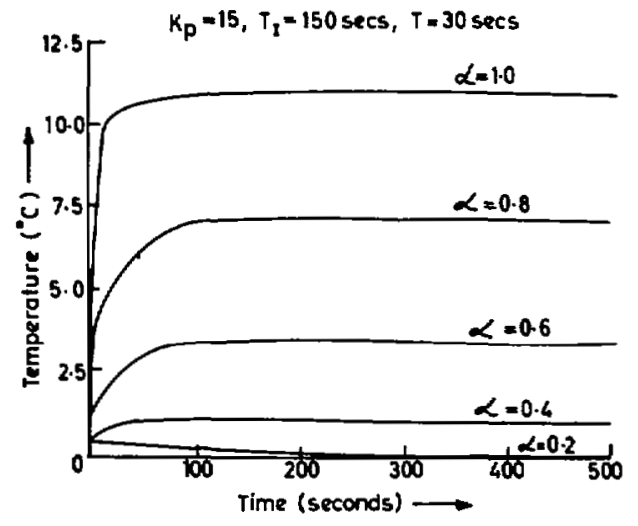

Fig. 2. Response with a discrete proportional-integral controller at the top end of the catalyst bed.

$$
m_{n}=K_{c}\left[e_{n}+T / T_{I} \sum_{k=0}^{n} e_{k}+T_{D} / T\left(e_{n}-e_{n-1}\right)\right] .
$$

The parameters $K_{c}, T_{l}$, and $T_{D}$ in (4) need to be tuned to obtain the desired response. Controller gains obtained using the root locus method are chosen as initial values and later tuned to get acceptable responses.

Fig. 2 shows the performance of the digital PI controller at the top end of the catalyst bed. A digital PID control algorithm used at the bottom end of the catalyst bed gives rise to the responses indicated in Fig. 3. These discrete controllers have poor disturbance rejection ${ }^{1}$ property at points other than the points of implementation. It is observed from simulation studies that the PID controller at the exit end of the reacting portion has a slow speed of response $(220 \mathrm{~s})$ and results in a maximum temperature change of 200 percent (expressed as a percentage of input disturbance of $5^{\circ} \mathrm{C}$ ). The choice of sampling time is an important aspect in the design of all discrete control algorithms since it can be regarded as one of the critical control parameters. Since the temperature variables under consideration have relatively slow dynamics, a choice of $30 \mathrm{~s}$ for the sampling time has proven quite reasonable. From Figs. 4 and 5, one can see that for sampling times of the order 60 and $80 \mathrm{~s}$, the response becomes either oscillatory or unstable.

\section{B. Discrete Multiloop Controller}

In many process control plants the practice is to ensure asymptotic regulation using PI and PID controllers in each loop. Following the analysis suggested by Shinskey [7], pairing of the input and output variables is done and catalyst bed top end temperature is controlled by the direct bypass flow rate and the bottom end one using the heat exchanger flow rate. A discrete version of the multiloop PI controllers is simulated and the parameters are tuned to get the desired response with minimum temperature offsets and overshoots, and fast settling times. Since there are four parameters for the two PI controllers

\footnotetext{
$1 \operatorname{lt}_{k \rightarrow \infty} y(k) \rightarrow 0$, i.e., the steady-state perturbed temperatures at the outputs due to the disturbances should be zero.
} 


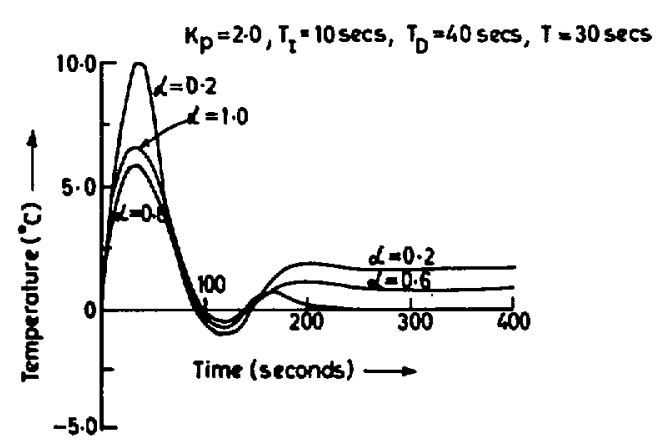

Fig. 3. Response with a discrete proportional-integral-derivative controller at the bottom end of the catalyst bed.

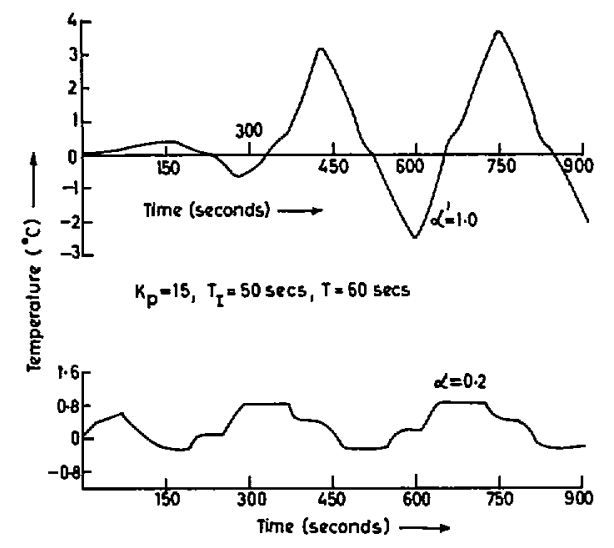

Fig. 4. Response with a discrete proportional-integral controller at the top end of the catalyst bed.

located at the top and bottom ends of the reactor, it is not feasible to attempt a parametric plot on a plane to obtain the stability boundaries. In the absence of any systematic design procedure, the gains that give a satisfactory performance are selected through extensive simulation studies. The responses for the chosen gains are plotted in Fig. 6. It is found from the simulation studies that the control system rejects disturbance at top and bottom ends of the reactor and has a settling time of $80 \mathrm{~s}$. The absolute values of maximum temperature changes along the length of the catalyst bed are smaller (maximum 70 percent) compared to the case where the point controllers are used at the top or bottom end of the reactor (maximum 210 and 176 percent, respectively).

\section{Discrete Quadratic Regulator}

The quadratic regulator theory offers a systematic method for the design of feedforward and integral controllers and this fact has been explored in a variety of application areas. However, the control laws obtained using this theory would require feeding back of all the state variables and generally require use of observers or Kalman filters for their implementation. For the reactor under consideration, however, all the state variables are available for measurement and hence the problem of estimating the state does not arise.

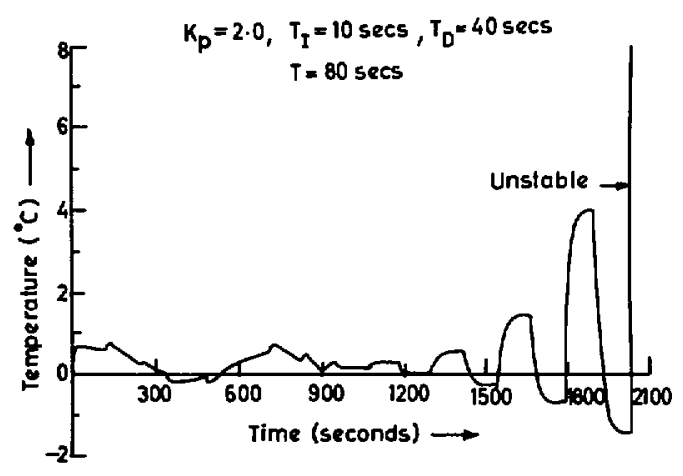

Fig. 5. Response with a discrete proportional-integral-derivative controller at the bottom end of the catalyst bed.

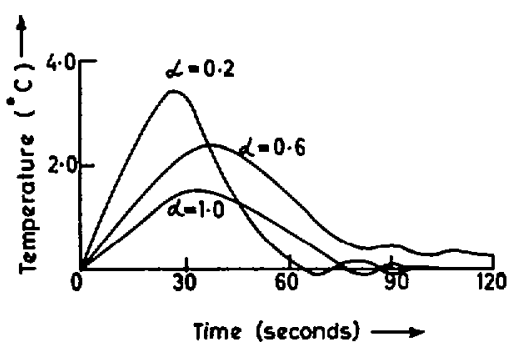

Fig. 6. Response with a discrete multiloop controller.

Consider the discrete-time linear system

$$
x(k+1)=\Phi x(k)+\Delta u(k) ; \quad y(k)=C x(k) \quad x(0)=x_{0}
$$

where $C$ is such that $C_{11}=C_{25}=1$ and the rest of the elements are zero. The objective here is to find the control sequence $u_{k}$ such that the following performance index is minimized

$$
J=\sum_{k=0}^{N-1} x^{T}(k+1) Q x(k+1)+u^{T}(k) R u(k) .
$$

In the above formulation $Q$ and $R$ are symmetric and positive semidefinite and positive definite matrices, respectively. The optimal control law is given by $u(k-1)=$ $-F(k-1) x(k-1), k=1,2, \cdots, N$, where the matrix $F(k$ $-1)$ is determined using standard formulas [6]. If $N$ is made sufficiently large, the feedback gain matrix $F(k-1)$ in the linear regulator becomes a constant matrix in the limit, permitting the control law implementation with constant feedback gains. Furthermore, since (3) is a completely controllable model, an appropriate choice of a $Q$ would yield a stable closed loop system. In the present problem $N, Q$, and $R$ are $50,50 I$, and $I$, respectively. With this choice, the $F$ matrix for a satisfactory response (110 s settling time, maximum overshoot of 80 percent, and maximum offset of 40 percent) is shown in Table $I$. But this pure proportional feedback gives offsets in the response. These can be eliminated by the addition of feedforward control or integral control as shown later. 
TABLE I

Gain Matrices for Quadratic Regulator Based ALgortthms

\begin{tabular}{|c|c|c|c|c|c|c|c|c|}
\hline$F=-\left[\begin{array}{l}0.71 \\
6.2\end{array}\right.$ & $\begin{array}{l}1.1 \\
1.7\end{array}$ & $\begin{array}{l}0.03 \\
1.0\end{array}$ & $\begin{array}{r}0.19, \quad-0.042, \\
-0.19, \quad-0.41, \\
\text { Proportional fer }\end{array}$ & $\begin{array}{r}0.0043 \\
-0.0042 \\
\text { edback }\end{array}$ & $\begin{array}{l}0.0, \\
0.0,\end{array}$ & & $\begin{array}{l}.051, \\
.040\end{array}$ & $\left.\begin{array}{r}0.072 \\
-0.037\end{array}\right]$ \\
\hline \multicolumn{9}{|c|}{$\begin{array}{l}F \text { matrix same as above } \\
L=\left[\begin{array}{cc}6.8091, & 1576.2 \\
1.1305, & -9528\end{array}\right] \\
\text { Feedback }+ \text { feedforward }\end{array}$} \\
\hline$F 1=-\left[\begin{array}{c}-0.13 \\
1.2\end{array}\right.$ & $\begin{array}{l}0.18 \\
0.19\end{array}$ & $\begin{array}{c}-0.018 \\
0.17\end{array}$ & $\begin{array}{r}-0.0008, \quad 0 \\
0.0077, \quad-0 \\
F 2=-\left[\begin{array}{rr}-0.0014, \\
0.054,\end{array}\right. \\
\text { Proportional }+\mathrm{i}\end{array}$ & $\left.\begin{array}{cc}0086, & 0.0 \\
.087 & 0.0 \\
0.0031 \\
0.011\end{array}\right]$ & & $\begin{array}{l}0.0 \\
0.0\end{array}$ & $\begin{array}{l}0.0088, \\
0.0076\end{array}$ & $\begin{array}{cc}3, & 0.012 \\
5, & -0.0067\end{array}$ \\
\hline
\end{tabular}

\section{A. Discrete Optimal Feedback Feedforward Controller}

Here, given the dynamic system [see (3)] and the performance index [see (5)], we seek a feedforward-feedback control law of the type $u_{k}=-F x_{k}-L d_{k}$ to achieve the objectives of stability and disturbance rejection. Here we find $F$ in the same way as in Section IV for the plant model when the disturbances are absent. The $L$ is found such that the steady-state output is zero using the formula

$$
L=\left[C(I-\Phi-\Delta F)^{-1} \Delta\right]^{-1} C(I-\Phi-\Delta F)^{-1} \theta .
$$

The indicated inverse in (6) exists if the system is stabilizable and if it has no zeros on the unit circle (see [6]). As discussed earlier in this section, these two conditions are met by the plant model (3). Thus, $F$ and $L$ can be obtained. Table I presents the elements of $L$.

Fig. 7 shows the simulation results. The overshoots exhibit a decreasing tendency with the increase of the elements of the $Q$ matrix, whereas they increase in size as the weight on the control effort (elements of $R$ ) is increased. The choice of these diagonal matrices with equal constants gives good response. So different weights in the diagonal elements were not tried.

\section{B. Discrete Optimal Proportional-Integral Controller}

To eliminate the steady-state offsets which arise when proportional control is used on systems subject to constant disturbances, proportional-plus-integral controllers can also be used.

Here we consider the design of PI controllers in the framework of the quadratic regulator theory. Define the discrete representation of the integral of $y(t)$ in the form $Z(k+1)=Z(k)+T C x(k)$. Augmenting this with (3), we obtain

$$
\begin{aligned}
x_{a}(k+1)=\Phi_{a} x(k)+\Delta_{a} u(k) & +\theta_{a} d(k) \\
& \text { with } x_{a}(k)=\left[x^{T}(k) Z^{T}(k)\right]^{T}
\end{aligned}
$$

Now, consider the problem of finding $u(k)$ which minimizes the performance index

$$
J=\sum_{k=0}^{N-1} x_{a}^{T}(k+1) Q_{a} x_{a}(k+1)+u^{T}(k) R u(k)
$$

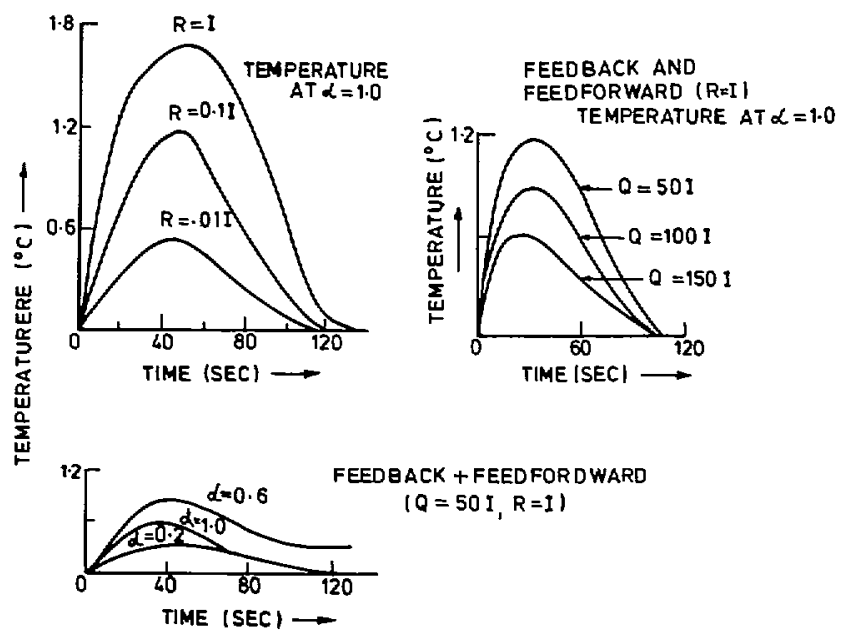

Fig. 7. Influence of weighting matrices on response.

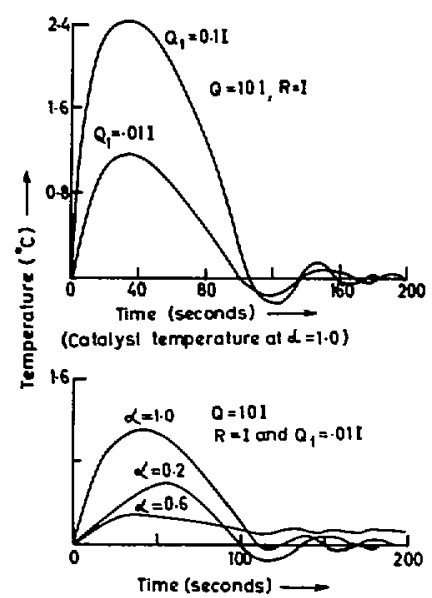

Fig. 8. Response with a discrete quadratic regulator (integral control).

where $Q_{a}=\operatorname{diag}\left(Q, Q_{1}\right)$ and $Q_{1}$ is the weighting matrix associated with the integral states. The feedback control law, then, is given by

$$
u(k)=-F_{1} x(k)-F_{2} Z(k) .
$$

This control law leads to a stable closed-loop system [6] provided: 1) $\left(\Phi_{a}, \Delta_{a}\right)$ is controllable and 2) $\left(\Phi_{a}, M_{a}\right)$ is observable, where $M_{a}$ is any matrix such that $M_{a}^{T} M_{a}=$ 
TABLE II

Comparative Performance of Computer Control Algorithms

(Percentages are calculated with respect to an input step of $5^{\circ} \mathrm{C}$ )

\begin{tabular}{|c|c|c|c|c|c|c|c|c|}
\hline \multirow[b]{2}{*}{$\begin{array}{l}\text { Sl. } \\
\text { No. }\end{array}$} & \multirow[b]{2}{*}{ Type of Controller } & \multicolumn{3}{|c|}{ Steady state offset in temperature at } & \multirow[t]{2}{*}{$\begin{array}{l}\text { Settling } \\
\text { time } \\
\text { (seconds) }\end{array}$} & \multicolumn{3}{|c|}{$\begin{array}{l}\text { Absolute value of maximum } \\
\text { temperature change at }\end{array}$} \\
\hline & & $\begin{array}{c}\alpha=0.2 \\
{ }^{\circ} \mathrm{C}\end{array}$ & $\begin{array}{c}\alpha=0.6 \\
{ }^{\circ} \mathrm{C}\end{array}$ & $\begin{array}{l}\alpha=1.0 \\
{ }^{\circ} \mathrm{C}\end{array}$ & & $\begin{array}{c}\alpha=0.2 \\
{ }^{\circ} \mathrm{C}\end{array}$ & $\begin{array}{c}\alpha=0.6 \\
{ }^{\circ} \mathrm{C}\end{array}$ & $\begin{array}{c}\alpha=1.0 \\
{ }^{\circ} \mathrm{C}\end{array}$ \\
\hline 1. & $\begin{array}{l}\text { Digital PI at } \alpha=0.2 \\
\left(K_{p}=15, T_{I}=150 \mathrm{~s},\right. \\
T=30 \mathrm{~s})\end{array}$ & 0 & $\begin{array}{c}3.24 \\
(64.8 \%)\end{array}$ & $\begin{array}{c}10.44 \\
(288 \%)\end{array}$ & 28 & $\begin{array}{c}0.60 \\
(12 \%)\end{array}$ & $\begin{array}{c}3.24 \\
(64.8 \%)\end{array}$ & $\begin{array}{c}10.44 \\
(288 \%)\end{array}$ \\
\hline 2. & $\begin{array}{l}\text { Digital PID at } \\
\alpha=1.0, K_{p}=1.5 \\
T_{I}=10 \mathrm{~s}, T_{D}=500 \\
\mathrm{~s}, T=30 \mathrm{~s})\end{array}$ & $\begin{array}{c}1.66 \\
(32.2 \%)\end{array}$ & $\begin{array}{c}0.83 \\
(16.6 \%)\end{array}$ & 0 & 220 & $\begin{array}{c}10.0 \\
(200 \%)\end{array}$ & $\begin{array}{c}6.0 \\
(120 \%)\end{array}$ & $\begin{array}{c}6.6 \\
(132 \%)\end{array}$ \\
\hline 3. & $\begin{array}{l}\text { Discrete multiloop } \\
\text { control }\end{array}$ & $\mathbf{0}$ & $\begin{array}{l}0.30 \\
(6 \%)\end{array}$ & $\mathbf{0}$ & 80 & $\begin{array}{c}3.5 \\
(70 \%)\end{array}$ & $\begin{array}{c}2.4 \\
(48 \%)\end{array}$ & $\begin{array}{c}1.6 \\
(32 \%)\end{array}$ \\
\hline 4. & $\begin{array}{l}\text { Discrete quadratic } \\
\text { feedback + feedforward }\end{array}$ & $\mathbf{0}$ & $\begin{array}{c}0.12 \\
(2.4 \%)\end{array}$ & $\mathbf{0}$ & 110 & $\begin{array}{c}0.32 \\
(6.4 \%)\end{array}$ & $\begin{array}{c}0.72 \\
(14.4 \%)\end{array}$ & $\begin{array}{c}0.6 \\
(12 \%)\end{array}$ \\
\hline 5. & $\begin{array}{l}\text { Discrete quadratic } \\
\text { integral }\end{array}$ & $\mathbf{0}$ & $\begin{array}{l}0.09 \\
(1.8 \%)\end{array}$ & 0 & 200 & $\begin{array}{c}0.64 \\
(12.8 \%)\end{array}$ & $\begin{array}{c}0.256 \\
(5.12 \%)\end{array}$ & $\begin{array}{c}1.12 \\
(22.4 \%)\end{array}$ \\
\hline
\end{tabular}

$Q_{a}$. The first condition is implied by the properties of the plant [see (3)] model, namely, controllability and absence of zeros on the unit circle and these two conditions are satisfied by system (3). The matrices $Q$ and $Q_{1}$ have been chosen so that the second condition is satisfied.

The gain matrices $F_{1}$ and $F_{2}$ are computed for different choices of $Q, Q_{1}$, and $R$. The choice $Q=10 I, Q_{1}=0.01 I$, and $R=I$ gives the best possible features, as can be seen from the hybrid simulation results presented in Fig. 8. The corresponding gain matrices $F_{1}$ and $F_{2}$ are tabulated in Table I. Also, it is observed that increase of the integralstate weight $Q_{1}$ results in a closed-loop system with larger overshoots and more oscillatory tendency.

\section{Concluding Remarks}

Comparison of the performance of various controllers considered here leads to the inference that the discrete quadratic regulator with feedforward and feedback control gives the best performance (see Table II). The integral controller suffers from the disadvantages of large overshoots, but in situations where disturbances cannot be measured accurately or measurement instrumentation is expensive, the integral controller may be the only feasible approach. Next, considering the choice between a multiloop controller and a quadratic regulator, it may be observed that the latter tends to be better in its performance because of the flexibility in tailoring it to produce the desired response, by a suitable choice of the weighting matrices. Even though the solution aspects of this problem are more complex, the process computer itself can perform the required "off-line" computations to provide the control algorithm. In summary, for the ammonia reactor, the quadratic regulator theory provides controllers that achieve faster regulation in the face of step disturbances. An alternate competitor, however, would be the state feedback-integral controllers designed using the pole placement theory.

\section{DYNAMIC MODEL OF THE REACTOR}

The method used is the same as that adopted by Brian et al. [5]. However, since the reactor configuration under consideration differs from the one considered in the above cited reference, appropriate modifications have been incorporated in the model equations. The proposed model consists of five partial differential equations and two algebraic equations with necessary boundary and initial conditions with respect to the space and time variables, respectively. The dynamic model is derived under the following assumptions.

1) There is no radial variation of temperature in the catalyst, cooling tube, and walls.

2) There is no temperature difference between the catalyst particles and the gas phase.

3) There is uniformly constant pressure throughout the converter.

4) There are negligibly small values of heat capacities of the tube walls in the reacting and heat exchanger section.

5) There is no heat loss from the shell side of the heat-exchanger to the environment.

6) There is an absence of longitudinal diffusion of the reactants in the reactor.

7) There is no transfer of enthalpy by conduction within the gas phase in the empty tube.

8) There is temperature independence of the heat capacity of the gases in the reactor only. The larger variation of temperature across the heat-exchanger warrants the calculation of these parameters from the exact expressions given by Shah et al. [8].

9) It is assumed that changes in flow rate, pressure and 
composition propagate instantaneously throughout the reactor. As a direct consequence of this assumption, this study is primarily concerned with transient analysis of the reactor for changes in the feed temperature.

All these assumptions have been validated in [3], [5], and [8] for ammonia reactors.

The material balance in the catalyst section is

$$
\frac{\partial y}{\partial \alpha}=\frac{V}{F} \frac{(1+y)^{2}}{\left(1+y^{*}\right)} r\left(T_{C}, y\right) .
$$

The energy balance in the empty tube section is

$$
\frac{\partial T_{T}}{\partial \alpha}=\frac{U S}{F \bar{C}_{p 0}}\left(T_{T}-T_{C}\right)
$$

The energy balance in the catalyst is

$$
\begin{aligned}
& \frac{-F}{h_{2} s_{2}}\left(\bar{C}_{p 0}-\Delta C \frac{y-y^{*}}{1+y}\right) \frac{\partial T_{C}}{\partial \alpha}+0.59\left(T_{T}-T_{C}\right) \\
& \frac{-F}{h_{2} s_{2}}\left(\Delta H_{0}-\Delta C\left(T_{C}-T_{B}\right)\right) \frac{\left(1+y^{*}\right)}{(1+y)^{2}} \frac{\partial y}{\partial \alpha}=\frac{\partial T_{C}}{\partial \theta} .
\end{aligned}
$$

The energy balance in the shell of the heat exchanger is

$$
\frac{\partial T_{S}^{\prime}}{\partial \theta}-\left(\frac{W C_{p c} \nu_{s}}{h_{2} s_{2} l^{\prime}}\right) \frac{\partial T_{S}^{\prime}}{\partial \alpha}=\left(\frac{W C_{p c}}{h_{2} s_{2}}\right) \frac{U^{\prime} S^{\prime}\left(T_{T}^{\prime}-T_{S}^{\prime}\right) \nu_{s}}{\delta \sum_{i=1}^{4} F F_{i} C_{p i}} .
$$

The energy balance in the tube of the heat exchanger is

$$
\frac{\partial T_{T}^{\prime}}{\partial \theta}+\left(\frac{W C_{p c} \nu_{T}}{h_{2} s_{2} l^{\prime}}\right) \frac{\partial T_{T}^{\prime}}{\partial \alpha}=-\left(\frac{W C_{p c}}{h_{2} s_{2}}\right) \frac{U^{\prime} S^{\prime}\left(T_{T}^{\prime}-T_{S}^{\prime}\right) \nu_{T}}{\sum_{i=1}^{4} f_{i}\left(\alpha^{\prime}, t\right) C_{p i}}
$$

Mixing equations and boundary conditions at the top of the reactor, the energy balance is

$$
\delta(1+\beta)\left(T_{T}(\alpha=0, \theta)\right)+\delta \beta \gamma\left(T_{F}(\theta)\right)=\left(T_{C}(\alpha=0, \theta)\right)
$$

and at the top of the heat exchanger, the energy balance is

$$
\delta\left(T_{S}^{\prime}\left(\alpha^{\prime}=0, \theta\right)\right)+\delta \beta\left(T_{F}(\theta)\right)=T_{T}(\alpha=1, \theta) .
$$

The boundary conditions are

$$
\begin{aligned}
y(\alpha=0, \theta) & =y^{*}(\theta) \\
T_{C}(\alpha=1, \theta) & =T_{T}^{\prime}\left(\alpha^{\prime}=0, \theta\right) \\
T_{S}^{\prime}\left(\alpha^{\prime}=1, \theta\right) & =T_{F}(\theta) .
\end{aligned}
$$

Equations $\left(1^{\prime}\right)-\left(10^{\prime}\right)$ describe the dynamics of the reactor-exchanger combination. In the above equations $\delta=$ $F_{1} / F, \beta=F_{2} / F_{1}$, and $\gamma=F_{3} / F_{2}$.

\section{APPENDIX II}

\section{Continuous State-Space Model for the Reactor}

In (1), $A, B$, and $D$ are given by

$$
\begin{aligned}
& A=\left[\begin{array}{ccccccccc}
-4.019, & 5.12, & 0, & 0, & -2.082, & 0, & 0, & 0, & 0.87 \\
-0.346, & 0.986, & 0, & 0, & -2.34, & 0, & 0, & 0, & 0.97 \\
-7.909, & 15.407, & -4.069, & 0, & -6.45, & 0, & 0, & 0, & 2.68 \\
-21.816, & 35.606, & -0.339, & -3.870, & -17.8, & 0, & 0, & 0, & 7.39 \\
-60.196, & 98.188, & -7.907, & 0.340, & -53.008, & 0, & 0, & 0, & 20.4 \\
0, & 0, & 0, & 0, & 94, & -147.2, & 0, & 53.2, & 0 \\
0, & 0, & 0, & 0, & 0, & 94, & -147.2, & 0, & 0, \\
0, & 0, & 0, & 0, & 0, & 12.8, & 0, & -31.6, & 0 \\
0, & 0, & 0, & 0, & 12.8, & 0, & 0, & 18.8 & -31.6
\end{array}\right] \\
& B=\left[\begin{array}{ccc}
0.010, & -0.011, & -0.151 \\
0.003, & -0.021, & 0 \\
0.009, & -0.059, & 0 \\
0.024, & -0.162, & 0 \\
0.068, & -0.445, & 0 \\
0, & 0, & 0 \\
0, & 0, & 0 \\
0, & 0, & 0 \\
0, & 0, & 0
\end{array}\right] \quad D=\left[\begin{array}{cc}
0.251, & -1438.916 \\
0.147, & -323.846 \\
0.405, & -82.771 \\
1.13, & -22.637 \\
3.07, & -5.456 \\
0, & 0 \\
53.2, & 0 \\
18.8, & 0 \\
0, & 0
\end{array}\right]
\end{aligned}
$$


Discrete State-Space Model for the Reactor

In (3), $\Phi, \Delta$, and $\Theta$ are given by

$\Phi=\left[\begin{array}{llll}0.8701, & 0.1350, & 0.1159 \times 10^{-1}, & 0.5014 \times 10^{-3}, \\ 0.7665 \times 10^{-1}, & 0.8974, & 0.1272 \times 10^{-1}, & 0.5504 \times 10^{-3}, \\ -0.1272, & 0.3575, & 0.8170, & 0.1455 \times 10^{-2}, \\ -0.3635, & 0.6339, & 0.7491 \times 10^{-1}, & 0.7966, \\ -0.9600, & 1.6459, & -0.1289, & -0.5597 \times 10^{-2}, \\ -0.6644, & 1.1296, & -0.8889 \times 10^{-1}, & -0.3854 \times 10^{-2}, \\ -0.4102, & 0.6930, & -0.5471 \times 10^{-1}, & -0.2371 \times 10^{-2}, \\ -0.1799, & 0.3017, & -0.2393 \times 10^{-1}, & -0.1035 \times 10^{-2}, \\ -0.3451, & 0.5804, & -0.4596 \times 10^{-1}, & -0.1989 \times 10^{-2},\end{array}\right.$

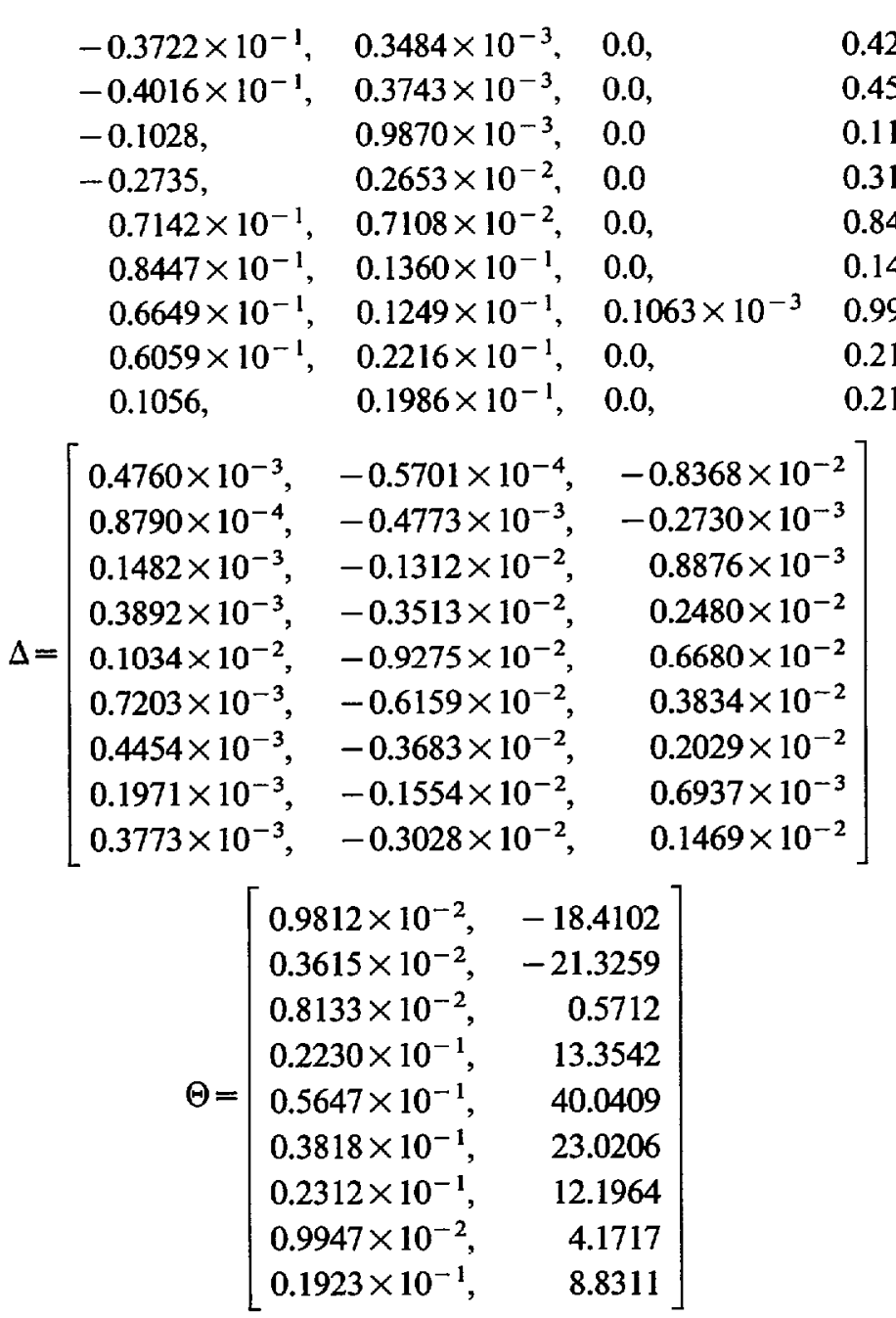

APPENDIX III

LIST OF SYMBOLS

$C_{p i} \quad$ specific heat of $i$ th component $(\mathrm{kcal} / \mathrm{kg} \cdot \mathrm{M} \cdot \mathrm{K})$ ( $i=1$ for hydrogen, 2 for nitrogen, 3 for ammonia, and 4 for inerts)

$\bar{C}_{p 0} \quad$ average heat capacity of feed gas $(\mathrm{kcal} / \mathrm{kg} \cdot \mathrm{M}$. K)

$\left.\begin{array}{ll}0.4242 \times 10^{-2}, & 0.7249 \times 10^{-2} \\ 0.4530 \times 10^{-2}, & 0.7499 \times 10^{-2} \\ 0.1185 \times 10^{-1}, & 0.1872 \times 10^{-1} \\ 0.3172 \times 10^{-1}, & 0.4882 \times 10^{-1} \\ 0.8452 \times 10^{-1}, & 0.1259 \\ 0.1443, & 0.1016 \\ 0.9997 \times 10^{-1}, & 0.6967 \times 10^{-1} \\ 0.2139, & 0.3554 \times 10^{-1} \\ 0.2191, & 0.2152\end{array}\right]$

$$
\text { . }
$$


equilibrium constant ( $1 / \mathrm{atm})$

pressure (atm)

heat transfer area in catalyst bed $\left(\mathrm{m}^{2}\right)$

heat transfer area in heat exchanger $\left(\mathrm{m}^{2}\right)$

reference temperature $\left(25^{\circ} \mathrm{C}\right)$

catalyst temperature $(\mathrm{K})$

feed temperature $\left({ }^{\circ} \mathrm{C}\right)$

temperature in the tube of catalyst portion $\left({ }^{\circ} \mathrm{C}\right)$ temperature in the tube of heat exchanger $\left({ }^{\circ} \mathrm{C}\right)$ temperature in the shell of heat-exchanger $\left({ }^{\circ} \mathrm{C}\right)$ overall heat transfer coefficient in catalyst bed $\left(\mathrm{kcal} / \mathrm{h} \cdot \mathrm{m}^{2} \cdot{ }^{\circ} \mathrm{C}\right)$

overall heat transfer coefficient in heat exchanger $\left(\mathrm{kcal} / \mathrm{h} \cdot \mathrm{m}^{2} \cdot{ }^{\circ} \mathrm{C}\right)$

volume of the catalyst bed $\left(\mathrm{m}^{3}\right)$

yield of ammonia $(\mathrm{kg} \cdot \mathrm{M} / \mathrm{h})$

catalyst activity factor

length of the heat exchanger (m)

reaction rate $\left(\mathrm{kg} \cdot \mathrm{M} \mathrm{NH} / \mathrm{h} \cdot \mathrm{m}^{3}\right.$ catalyst)

mole fraction of ammonia

mole fraction of hydrogen

mole fraction of nitrogen

mole fraction of inerts

normalized distance (catalyst section)

normalized distance (heat exchanger)

decrease in specific heat due to formation of 1

$\mathrm{M}$ of ammonia $(\mathrm{kcal} / \mathrm{kg} \cdot \mathrm{M} \cdot \mathrm{K}$ )

enthalpy of formation of ammonia at $298 \mathrm{~K}$ $(\mathrm{kcal} / \mathrm{kg} \cdot \mathrm{M}$ )

$h_{1}$ average heat transfer coefficient from wallempty tube $\left(\mathrm{kcal} / \mathrm{h} \cdot \mathrm{m}^{2 \circ} \mathrm{C}\right)$

average heat transfer coefficient from wall-catalyst section $\left(\mathrm{kcal} / \mathrm{h} \cdot \mathrm{m}^{2} \cdot{ }^{\circ} \mathrm{C}\right)$

nondimensional unit of time

\section{weight of catalyst $(\mathrm{kg})$}

specific heat of catalyst $(\mathrm{kcal} / \mathrm{kg} \cdot \mathrm{M} \cdot \mathrm{K}$ )

heat transfer area between wall-catalyst section $\left(\mathrm{m}^{2}\right)$

velocity of the gas mixture in the shell side of heat exchanger $(\mathrm{m} / \mathrm{s})$

velocity of the gas mixture in the tube of heat exchanger $(\mathrm{m} / \mathrm{s})$

$t_{c}(i), i=1,5$ incremental catalyst temperature at $i$ th location $\left({ }^{\circ} \mathrm{C}\right)$

$t_{t}^{\prime}(i), i=1,2$ incremental tube temperature in heat exchanger at $i$ th location $\left({ }^{\circ} \mathrm{C}\right)$

$t_{s}^{\prime}(i), i=0,1$ incremental shell temperature in heat exchanger at $i$ th location $\left({ }^{\circ} \mathrm{C}\right)$

$u_{1}, u_{2}, u_{3}$ incremental flow rates (manipulated variables) $(\mathrm{kg} \cdot \mathrm{m} / \mathrm{h})$ for $F_{1}, F_{2}$, and $F_{3}$, respectively.

$t_{f} \quad$ incremental feed temperature $\left({ }^{\circ} \mathrm{C}\right)$

$y_{0} \quad$ incremental feed composition

$T \quad$ sampling time (s)

$K_{c} \quad$ proportional gain

$T_{I} \quad$ reset time (s)
$T_{D} \quad$ derivative time (s)

$e_{n} \quad$ error at the $n$th sampling period

$e_{n-1} \quad$ error at the $(n-1)$ st sampling period

$m_{n} \quad$ the manipulated variable at the $n$th sampling period.

* $\quad$ inlet condition.

\section{ACKNOWLEDGMENT}

The authors would like to thank the reviewers for their valuable comments.

\section{REFERENCES}

[1] L. M. Patnaik, N. Viswanadham, and I. G. Sarma, "Identification and optimization of ammonia reactors through hybrid simulation," in Proc. 1977 IEEE Conf. Decision and Control, 1977. p. 185.

[2] S. S. Gluzman and V. N. Krainov, "A study of the dynamic properties of the direct digital control system for the ammonia synthesis process," Int. Chem. Eng. vol. 7, p. 289, Apr. 1967.

[3] B. W. Ijin, D. Balzer, G. Reinig, and V. Schol, "Feedback control of ammonia synthesis converter via temperature field estimation," Preprints of IFAC Symp. Digital Simulation of Continuous Process, 1971, Paper I1.

[4] L. M. Patnaik, "Optimization and multivariable computer control of an ammonia reactor," Ph.D. dissertation, Indian Inst. Sci, Bangalore, India, Dec. 1977.

[5] P. L. T. Brian, R. F. Baddour, and J. P. Eymery, "Transient behaviour of an ammonia synthesis reactor," Chem. Eng. Sci. vol. 20 , p. 297,1965 .

[6] H. Kwakernak and R. Sivan, Linear Optimal Control Systems. New York: Wiley-Interscience, 1972.

[7] F. G. Shinskey, "The stability of interacting control loops with and without decoupling," Preprints IV Int. Symp. Multioariable Techn. Syst., 1977, p. 21.

[8] P. Uronen, "Modelling and simulation of catalytic autothermic gas reactors," Acta Polytechnica Scandinavica, ch. 105, 1971.

[9] P. W. Staats and J. B. Pearson, "Robust solution of the linear servomechanism problem," Automatica, vol. 13, p. 125, Mar. 1977.

[10] N. Viswanadham, L. M. Patnaik, and I. G. Sarma, "Robust multivariable controllers for a tubular ammonia reactor," $A S M E$ J. Dynamic Syst., Measurement and Control, vol. 101, p. 290, Dec. 1979.

[11] L. A. Gould and F. M. Schlaepfer, "Modal control of an ammonia reactor," Proc. 1967 JACC, p. 81.

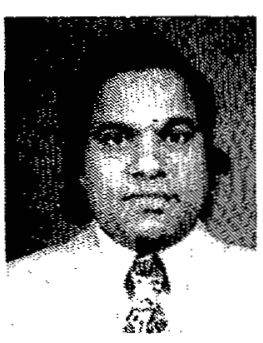

L. M. Patnalk received the B.Sc. (Eng.) degree with first rank from the Regional Engineering College, Rourkela, in 1969, and the M.E. degree with Distinction and $\mathrm{Ph} . \mathrm{D}$. degree, both from the Indian Institute of Science, Bangalore, in 1971 and 1977 , respectively.

From October 1971 to March 1976 he was a Senior Research Assistant in the School of Automation, Indian Institute of Science. During this period he was involved in teaching, research, and laboratory development activities in the areas of instrumentation, industrial control, computer control of industrial processes, digital system design, and computer simulation. Since April 1976 he has been serving as a Systems Programmer in the Hybrid Computer Laboratory, Indian Institute of Science. Currently he is an Assistant Professor in the School of Automation at the Institute. He has been a Consultant to a few industrial organizations including the Electronics Corporation of India Ltd. and Larsen and Toubro Ltd. His research and development interests are in the areas of real time control, modeling and simulation, computer organization and architecture, microprocessor applications, performance evaluation of computing systems, computer graphics and database management systems. 
Dr. Patnaik is a member of the Computer Society of India and was a member of the AdCom for the IEEE-IECI (India) group during 1974 to 1975.

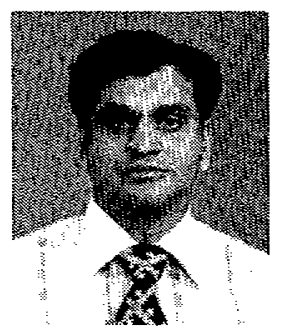

N. Viswanadham was born in Anathavaram, India, in 1943. He received the B.Sc. degree from Andhra University Waltair, India, in 1961, and the B.E., M.E., and Ph.D. degrees in electrical engineering from the Indian Institute of Science, Bangalore, India, in 1964, 1966, and 1970, respectively.

Since 1967 he has been on the faculty of the Indian Institute of Science. He is currently an Assistant Professor in the School of Automation. His main research interests are in large scale and system theory and its applications in power and communication networks.

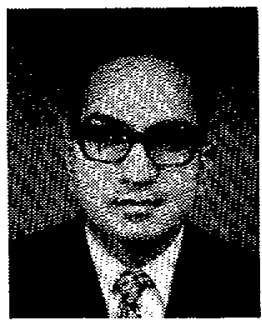

Isukapalli G. Sarma was born in Chandalur, India, in 1936. He received the M.E. degree from the Indian Institute of Science, Bangalore, and the Ph.D. degree from the University of Wisconsin, Madison, in 1960 and 1964, respectively.

From 1964 to 1970 he served on the faculty of the Indian Institute of Technology, Kanpur. Since 1970 he has been a Professor in the School of Automation, Indian Institute of Science, and served as its Chairman from 1971 to 1979 . His current research interests include digital and hybrid computer simulation and industrial control applications of digital computers.

Prof. Sarma is a Fellow of the Indian Academy of Science, a member of the IFAC Mathematics of Control Committee, and Vice Chairman of the IEEE (India) Bangalore section. He received the Vikram Sarabhai Medal for outstanding contributions to the field of system analysis in 1977.

\title{
Resource Management for Large Systems: Concepts, Algorithms, and an Application
}

\author{
RAJAN SURI, MEMBER, IEEE, AND YU-CHI HO, FELLOW, IEEE
}

\begin{abstract}
Certain resource-allocation problems encountered in large operational systems are characterized as the resource management (RM) problem. Known Lagrange multiplier techniques for decentralization of large problems are then extended to large "real-world" problems, where functions and sets may be ill behaved. Simple conditions are given for existence of suitable multipliers, and provably convergent solution algorithms are also presented. These results are based on novel sets of assumptions; an attempt is made to justify these as an alternative for analyzing large real-world systems. Application of these concepts and algorithms to a large spare-parts warehouse is described.
\end{abstract}

\section{INTRODUCTION}

$\mathrm{T}$ HE study of large-scale systems and decentralized control is becoming increasingly important today [2]. Here we study the application of decentralization to one aspect of such systems, namely the problem of resource

Manuscript received December 6, 1978; revised September 12, 1979 and February 7, 1980. Paper recommended by W. R. Perkins, Chairman of the Economic and Social Systems Committee. This work was supported in part by FIAT Ricambi, in part by the U.S. Office of Naval Research under JSEP Contract N00014-75-C-0648, and in part by the National Science Foundation under Grant ENG 78-15231.

The authors are with the Division of Applied Sciences, Harvard University, Cambridge, MA 02138. management (RM) in large systems. $R M$ is defined below as a certain class of resource-allocation problems. Our motives for studying RM problems are manifold. Firstly, several large operational systems (e.g., computer networks or warehouses) have resource-allocation problems which fall naturally into the class of RM problems. Secondly, although Lagrange multiplier techniques for decomposition of large allocation problems are well known, they suffer from the possibility of duality "gaps," which means there may not exist multipliers which generate the optimum. To guarantee the absence of "gaps" various functions are required to be convex, which is too restrictive for many "real-world" problems. In the case of large RM problems however, we show that less restrictive conditions can be formulated. Thirdly, known large scale mathematical programming algorithms can be fairly slow when applied to very large allocation problems [15]. For large RM problems on the other hand, our experience has shown that more efficient algorithms can be constructed, even though the problems are essentially integer programming in nature. Here we describe one such algorithm and attempt to give alternative sets of assumptions which can explain the success of this approach even in the absence 